

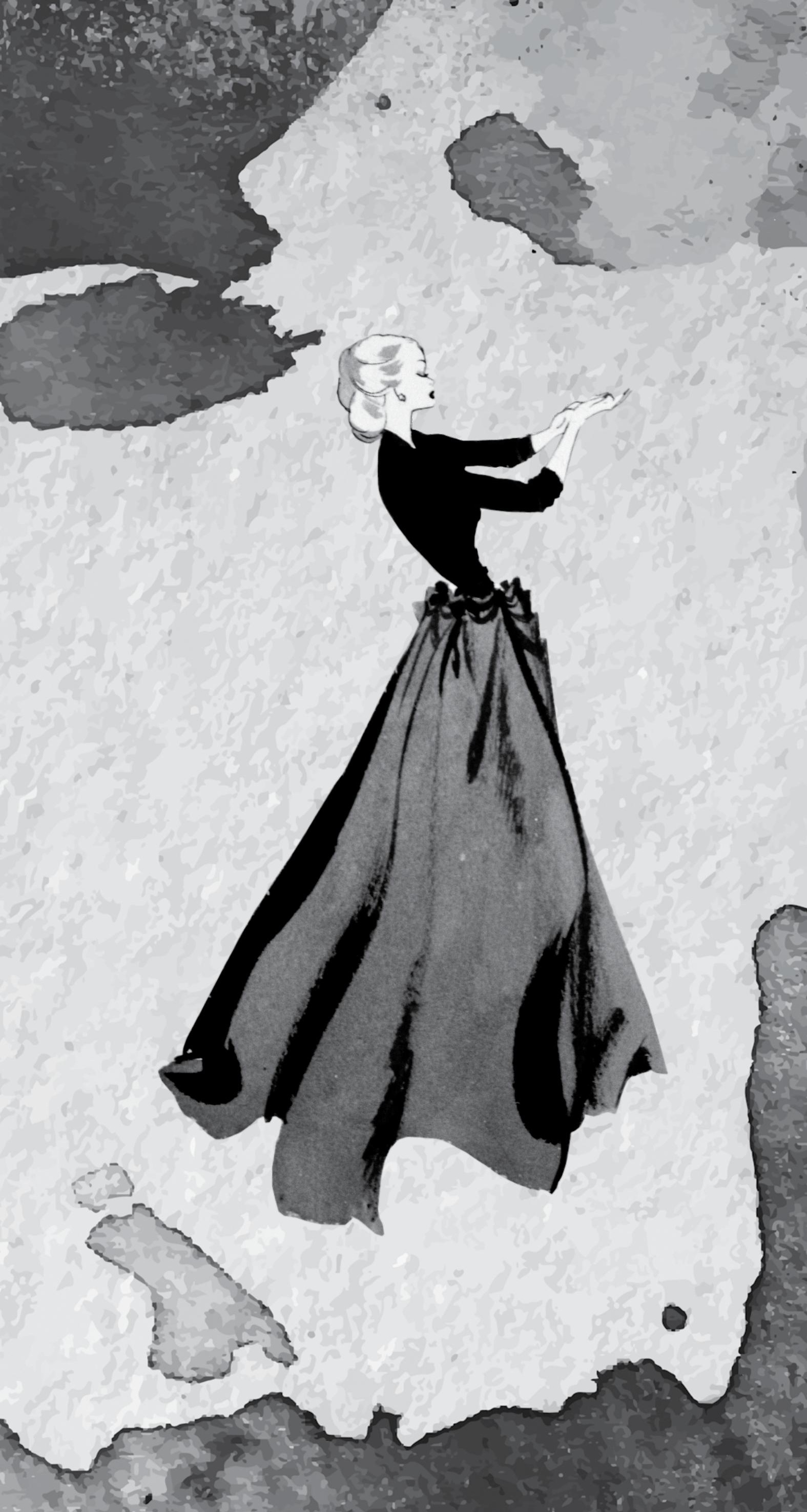


traduções]

[REGINA A. ROOT]

The College of William and Mary, USA.

raroot@wm.edumailto:raroot@wm.edu

\title{
Ferramentas poderosas para um manifesto da moda ${ }^{1}$
}

\author{
Título original: Powerfull tools: Towards a \\ fashion manifesto. 0 ensaio original apareceu \\ na edição de maio/junho de 2013 da $L a$ \\ Tempestad, 15: 90, pp. 106-111. Uma versão do \\ mesmo trabalho foi publicada no International \\ Journal of Fashion Studies. 1: 1, pp. 119-126.
}

Pois as ferramentas do dono jamais destruirão a casa do dono. (Audre Lorde, 2007, p. 112)

A moda é uma poderosa ferramenta cultural que transmite múltiplos significados. Ela rearticula o passado, inspira a expressão criativa, provoca a mudança e produz significado por intermédio dos agenciamentos de quem a veste. A canção "Thrift Shop", de Macklemore e Ryan Lewis, conta em detalhes a ação popular de procurar em pilhas de roupas descartadas, praticada pessoas que querem pagar barato para ter uma aparência cool.

Mas, como a maior parte da moda contemporânea e da cultura popular, a alma das pessoas que fizeram, ou um dia vestiram essas roupas permanece esquecida, pois elas são a contraparte humana da realidade descartada ao longo da cadeia de suprimentos. 0 self-fashioning, entendido como ação contra a corrente e por entre as armadilhas da tolerância, é sempre uma apropriação. Dentro do capitalismo global, nossas roupas atravessam fronteiras e viajam o mundo durante sua criação, produção, seu consumo e, às vezes, seu refashioning. Além disso, as roupas representam histórias ricas e significativas. Como, então, retratar o espírito humano e tornar visiveis os custos emocionais de uma narrativa maior do consumo global?

Embora o uso da moda tenha sido tradicionalmente circunscrito pela geografia, como o exame localizado de roupas de segunda mão ou estilos de vestir nacionais, a agência hoje em dia acontece no palco global. Os fluxos do turismo internacional e da globalização tornaram imperativo para o design ser relevante para as comunidades que representa e serve. Governos de todo o mundo têm criado ou promovido, recentemente, novos paradigmas culturais, com sérias implicações para o design e as indústrias criativas em geral. À medida que os profissionais de design inovarem para o futuro, entretanto, fica bastante claro que o próximo passo de sucesso dessa "moda para o futuro" está diretamente relacionado à lucratividade. Quando designs contemporâneos se apropriam dos emblemas da herança cultural, elas acabam se tornando citações irônicas em uma busca obsolescente, mesmo que os objetivos sustentáveis de preservar a diversidade cultural e conservar o ambiente para futuras gerações sejam alardeados. Para os muitos artesãos empregados pelo mercado global, as afiliações à identidade cultural no design só se desvalorizam quando modelos de produção são utilizados para manipular formas de arte$^{2}$. 
Como Audre Lorde (2007, p. 111) argumenta em outro contexto, "defender a mera tolerância da diferença" nega "a função criativa da diferença". Embora a moda possa servir como ferramenta criativa por meio da qual realizamos uma troca cultural significativa, conforme evidenciado com a proliferação das semanas de moda, exposições comerciais e outros shows de moda, ela também depende das "ferramentas do dono", como tornar o Outro exótico, sem efetuar nenhuma mudança social significativa. Projeções de multiculturalismo na moda poderiam permitir que se ponderasse a tolerância de modo mais elaborado, talvez pela leitura de uma revista de moda, mas tais ações não defendem a inclusão nem a aceitação de todas as culturas e suas lógicas político-econômicas. Como, então, podemos trabalhar para minimizar o dano e tornar aparente a essa vulnerabilidade? Precisa-se, desesperadamente, de um projeto de descentralização nos estudos de moda global para responder essa e outras questões. Um estudo da "arqueologia do conhecimento"3 ${ }^{13}$ parece particularmente urgente, com uma reavaliação de modas históricas, políticas culturais e inovações de design entre culturas e ao longo do tempo. 0 mito de que a moda começou como uma resposta à modernidade europeia permeia o campo há tempo demais4.

As influências múltiplas e sobrepostas na moda latino-americana, embora jamais confinadas às origens neste hemisfério, foram moldadas drasticamente pela globalização. Como o vestuário convida corpos individuais e coletivos a assumirem identidades culturais distintas, os fluxos globais em expansão têm levado a herança cultural para a esfera internacional. Os estudiosos da moda geralmente não discutem o que as apropriações da herança cultural latino-americana significam em relação ao papel de um designer no processo de construção da moda. Quando um designer como Jean Paul Gaultier se apropria, em suas coleções de alta-costura, do icônico chapéu-coco usado pelas mulheres quéchuas e aymaras na Bolívia (sendo esse chapéu já uma apropriação do estilo inglês) ou do sombrero vueltiao colombiano (um chapéu de duas cores com voltas de folhas de cana bordadas, uma técnica conhecida como caña flecha) esse ato representa uma inovação criativa prévia ou sinaliza o privilégio de selecionar e distinguir por parte do designer? Quando um designer estrangeiro "descobre" e reinterpreta a tradição, como os designers latino-americanos contemporâneos reavaliam esses mesmos emblemas de herança cultural? Nos registros de história da moda, como se consegue legitimação sobrepondo o outro? Numerosas iniciativas colocadas em prática a caminho na região posicionam a "moda" como significantes culturais relevantes para as comunidades que representa, emprega e serve. Designs criativos reagem cada vez mais ao influxo de bens globais que transformaram a cultura e a economia. A instituição das semanas de moda como evento anual em muitos paises é um desenvolvimento bastante significativo. Desde 2009, quando diversos paises latino-americanos iniciaram as comemorações do bicentenário, as semanas de moda começaram a levar o design para o terceiro século de independência ${ }^{5}$.

Antecipando as comemorações, jovens designers, na lxel Moda, congresso de moda que reúne acadêmicos e pessoas do setor produtivo, apresentaram, em Cartagena de Índias ${ }^{6}$ Colômbia, suas visões de uma "sustentabilidade bicentenária" na passarela e reimaginaram a independência à luz contemporânea dos atuais abusos dos direitos humanos, disparidades econômicas, perda de identidade cultural e crises ecológicas iminentes. Com materiais tão variados quanto pneus velhos de veículos militares e gazes de fibra natural, jovens designers criaram roupas pelo processo de upcycling. 0 barrete frígio da liberdade, usado durante os movimentos de independência, agora ornava as cabeças dos cidadãos con- 
temporâneos, talvez feito de gaze para dar a entender a existência de uma ferida recente. Um dos vestidos apresentava uma estampa colorida de Simón Bolivar, o líder do século XIX, cujos sonhos de um esforço revolucionário unificado levaram à libertação da América do Sul da opressão colonial espanhola. Outras roupas evocavam amor, paixão, paz e empoderamento, ferramentas poderosas usadas para emergir da guerra contra as drogas na Colômbia?

Se a moda pode servir como ferramenta de mudanças, então é preciso entender a mudança como uma série de negociações e processos. Essa lógica torna vital, então, desvendar a narrativa da herança cultural. Marcas internacionais de luxo podem desenterrar as raízes antigas da moda de muitas regiões culturalmente diferentes do mundo, mas isso não faz mais do que lançar um olhar superficial às camadas da história. Quando os designers citam o poncho folgado, as armadilhas da tolerância dão a entender que os significados de um estilo anterior à chegada dos europeus permanecem, em grande parte, ignorados. $E$ isso nega à roupa suas possibilidades como emblema de identidade cultural e possibilidades utópicas. Mariano Breccia e Mechi Martínez, os artistas têxteis argentinos da 12- $\mathrm{N}^{\mathrm{a}}$, que utilizam roupas descartadas desde 2004, remodelam fragmentos usados em novas camadas de história.

Sua coleção de 2013, que evoluciona de ponchos inspirados nos jovens pelo processo de design coletivo, anuncia uma pegada urbana com referências à mitologia andina. A partir de roupas usadas das décadas de 1970, 1980 e 1990, os artistas desconstroem as peças de roupas existentes, tais como camisetas para turistas e suéteres velhos, apenas para reconstrui-las e comunicar novos significados. Conectando redes de consumo urbano a uma ecologia maior da cadeia de suprimento multinacional, esses designers executam intervenções têxteis centrais à nova agência que emerge por todas as Américas. Usar o poncho não basta. Para a 12- $\mathrm{N}^{\mathrm{a}}$, o processo de design deve envolver um elemento de ação coletiva, como quando, aquele que veste a roupa, se junta ao ato de reunir os fragmentos de história para criar um ícone da identidade sul-americana com diversas camadas temporais e que significa algo. Ao mesmo tempo, esse projeto é um exercício na construção de uma roupa por meio de paisagens nativas e lendas andinas, conforme ilustrado em Kusiclos ${ }^{8}$, que funde elementos de herança cultural e pode de fato revelar os mesmos limites de outras práticas da moda.

Para vários designers, o conceito "somos o que vestimos" vai muito além dos materiais. Oferecer salários justos aos produtores de vestuário, integrar conhecimento local ao processo de design e educar os consumidores quanto às implicações sociais das escolhas de estilo de vida são de um mérito cada vez maior. $\mathrm{Na}$ indústria de moda colombiana em expansão, por exemplo, Adriana Santacruz tem trabalhado lado a lado com tecelãs indigenas para conservar técnicas tradicionais, e, ao mesmo tempo, empoderar as que foram retiradas do interior atingido pela guerra (que antes do acordo de paz de 24 de agosto 2016 dividia o país) para que adquiram voz e poder junto com uma fatia do mercado ${ }^{9}$. 0 Mercado de Industrias Culturales Argentinas (MICA), iniciativa do governo que promove práticas de design com base na comunidade e centradas ao redor de manufaturas individuais e de pequena escala, foi criado com a intenção de evitar práticas de trabalho exploratórias e posicionar o designer como facilitador dentro de um processo de produção maior. Como está escrito no website do Ministério da Cultura da Argentina, "produzir é criar, fazer, representar". 0 problema com iniciativas do governo que produzem impacto sobre o design, entretanto, é que elas rapidamente se tornam exemplos da eficiência do Estado. Embora seja nobre pensar em democratizar a cultura e tornar visíveis os setores tradicionalmente omitidos dos pontos oficiais, o mapa cultural é, na realidade, uma história de profundas conexões humanas que transcendem qualquer paradigma nacional ou transnacional. 
Provavelmente, o maior desafio para qualquer tendência futura de moda seja a natureza multinacional da cadeia de suprimentos da moda. Roupas produzidas em sweatshops, oficinas onde as costureiras trabalham sob regime praticamente escravo, custam um preço enorme em termos humanos e ambientais. Dentro do contexto da cultura popular, alguns documentários, como Made in L.A. (2007), mostram o labor dos setores mais invisiveis da força de trabalho da indústria, nesse caso, imigrantes mexicanos e centro-americanos sem documentação que trabalharam uma época para uma subcontratante da Forever 21, na parte leste de Los Angeles. São imagens polêmicas das condições do trabalhador da indústria global do vestuário, imagens raramente realçadas de maneira significativa em seções de estilo ou como as facetas integradas do jornalismo de moda. No fim do ciclo de vida de uma peça de roupa, os praticantes culturais descobrem que as questões éticas ainda predominam, conforme evidenciado por Ropa Americana (2003), um documentário que faz referência a roupas norte-americanas usadas, vendidas na América Central, e acompanha a jornada de uma camiseta roxa manchada por alvejante e indesejada que foi doada à instituição de caridade canadense Goodwill até o closet de uma dona de casa da Costa Rica. Esses documentários são meras representações e não substituem a experiência vivida. Mas revelam necessidades e aspirações da comunidade que deveria colocar o valor do comércio justo e da preocupação pelos direitos humanos na linha de frente do design de moda do futuro e de outras iniciativas criativas ${ }^{10}$.

Como Audre Lorde (2007) escreve, em outro contexto, mas com palavras que eu escolheria como mantra para qualquer manifesto de moda digno de seu nome:

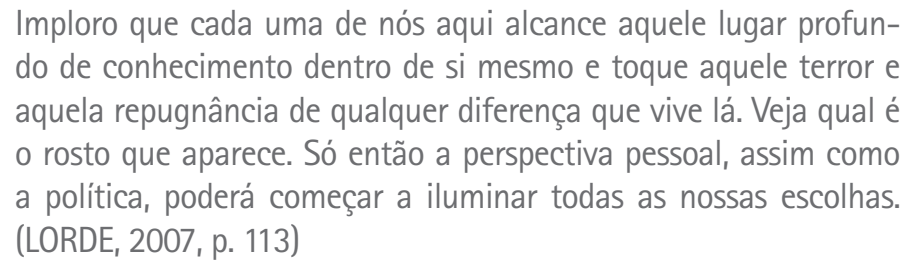

Então, que tipo de histórias suas roupas contam? Como podemos usar as ferramentas para desmontar conceitos que tornaram outras pessoas invisiveis, mesmo quando sua cultura está sendo exibida? Como podem profissionais criativos reimaginar novos estilos e um processo de design que seja verdadeiramente inclusivo? Em outras palavras, o que você estará vestindo na revolução da moda? 


\section{NOTAS}

[1] Tradução: Fábio Fernandes

[2] No recém-publicado Handbook of Fashion Studies, Mary Littrell e Judy Frater (2013) revelam como empreitadas artesanais, com base na educação e nos direitos humanos, ajudam trabalhadores a recuperar o orgulho de suas habilidades, e se tornarem intérpretes ativos em termos de herança ou propriedade intelectual - para criar bibliotecas têxteis que preservem a memória cultural e ofereçam inspiração para novos designs -, além de aprender como alcançar mercados que valorizem seus produtos.

[3] Uma referência na metodologia histórica que rompe com as exclusões de uma gramática e a lógica que projeta continuidades históricas do conhecimento. Saiba mais em: FOUCAULT, Michel. The Archaeology of Knowledge. Paris: Editions Gallimard, 1969.

${ }^{[4]}$ Como explico no The Handbook of Fashion Studies (ROOT, 2013a), a tendência a associar moda com poder de interpretação marginaliza ainda mais as expressões criativas das culturas sujeitas a invasões coloniais e a práticas de exploração da apropriação cultural na globalização contemporânea, todos tópicos de significação crítica para a área.

${ }^{[5]}$ Em 2009, Bolivia e Equador iniciaram as comemoraç̃es que se seguiram na Argentina, no Chile, Colômbia, México e Venezuela, em 2010, e no Paraguai, em 2011. Esse processo continuará por toda a região, e o Brasil se prepara para comemorar seu bicentenário em 2022.

6] Entre 2008 e 2015, o congresso ocorreu anualmente. Em 2015, a organização do evento decidiu tornar o congresso bienal. Disponivel em: <http://www.ixelmoda.com/web/index.html>. Acesso em: 9 set. 2016.

[7] Para uma análise expandida dessa coleção específica das passarelas, ver Root (2013b).

${ }^{[8]}$ Os kusillos são personagens da cultura aymara, da Bolívia, que, em épocas de semeadura, bailam com trajes e máscaras feitos com roupas recicladas pedindo por uma colheita abundante. A 12- $\mathrm{N}^{\mathrm{a}}$ reinterpretou essas vestimentas em uma coleção chamada Kusiclos (2011).

[9] Em San Juan de Pasto, capital do município de Nariño, Colômbia, a designer Adriana Santacruz iniciou um projeto de pequena escala com cinco tecelãs indígenas, em 1999. Essa colaboração cresceu e se tornou um empreendimento lucrativo, que concentra a energia das tecelãs com as silhuetas elegantes inspiradas pelo poncho ruana colombiano e outras formas de vestuário indígena. Situada ao longo da fronteira entre 0 Equador e a Colômbia, Nariño foi local de uma terrivel violência, resultado de uma disputa entre guerrilhas de esquerda, grupos paramilitares, os militares colombianos e traficantes de drogas. Comunidades indigenas e afro-colombianas sofreram deslocamentos em massa de suas terras, segundo o Los Angeles Times. Projetos de design sustentável, como o executado por Santacruz, foram criados para oferecer aos colombianos deslocados um emprego produtivo, permitindo, especialmente às tecelãs, que conservem sua herança cultural e também fornecendo esperança para seu futuro dentro de uma indústria de moda colombiana em expansão.

${ }^{[10]}$ Identidades productivas. Disponivel em: <http://identidades.cultura.gob.ar/>. Acesso em: 10 abr. 2014.

\section{REFERÊNCIAS}

FOUCAULT, Michel. The Archaeology of knowledge. Paris: Editions Gallimard, 1969.

LITTREL, Mary; FRATER, Judy. Artisan enterprise, cultural property and the global market. In: BLACK, Sandy et. all (Eds.). The handbook of fashion studies. Oxford: Bloomsbury, 2013, pp. 371-390.

LORDE, Audre. The master's tools will never dismantle the master's house. In: Sister outsider: essays and speeches. Berkeley: The Crossing Press, 2007, pp. 110-114.

ROOT, Regina A. Introduction to section on "Fashion, Agency, Policy". In: BLACK, Sandy et all (Eds.). The handbook of fashion studies. Oxford: Bloomsbury, 2013a, pp. 347-352.

ROOT, Regina A. Mapping Latin American fashion. In: BLACK, Sandy et all (Eds.). The handbook of fashion studies. Oxford: Bloomsbury, 2013, pp. 391-407. 